\title{
Surface Tension of Molten Alkali Silicates
}

\author{
Leo Shartsis and Sam Spinner
}

\begin{abstract}
The surface tensions of a series of lithium, sodium, and potassium silicate melts were measured by a maximum-pull-on-cylinder method. The order $\mathrm{Li}>\mathrm{Na}>\mathrm{K}$ was established for surface tension as well as for the algebraic value of the temperature coefficient of surface tension. Lithia and soda raised the surface tension, and potash lowered it. The surface tension curves of different alkali content converged with increasing temperature for lithium and sodium, but diverged for potassium silicates. Liquids containing less than 33 mole percent of lithia had positive temperature coefficients of surface tension. Correlation was observed between alkali content, volume expansivity, and temperature coefficient of surface tension.
\end{abstract}

\section{Introduction}

One of the fundamental aims of the scientific study of glass-forming systems is to find relationships between composition and properties that will lead to a better understanding of the glassy state. For this purpose, studies of the change in properties resulting from systematic variations in composition of simple glass-forming systems are necessary. In planning: such experiments, it is neither necessary nor desirable to limit the composition range to formulations where glasses are readily formed on cooling. In many such systems, the glass-forming region shades off gradually into the non-glass-forming region, and useful information may be obtained by extending the formulations range beyond the glass-forming region.

Surface tension is one of the physical properties of glass-forming materials that is related to certain working properties of glasses. These properties include the fining of glass (removal of bubbles), healing of glass blisters, the adhesion of hot glass to hot glass and other heated solids, the fire polishing of rough edges and surfaces, etc.

The common constituent of practical glasses is $\mathrm{SiO}_{2}$. Unfortunately, there are not many oxides that can be conveniently added alone to $\mathrm{SiO}_{2}$ to form glasses. However, the alkaline oxides, $\mathrm{Li}_{2} \mathrm{O}, \mathrm{Na}_{2} \mathrm{O}$, and $\mathrm{K}_{2} \mathrm{O}$, are among those that form binary glasses with $\mathrm{SiO}_{2}$, and a study of these systems was undertaken. The objectives of this investigation were to determine (1) how the surface tension varied with composition and temperature, (2) how the temperature coefficient of surface tension varied with composition, and (3) how the temperature coefficient of surface tension varied with expansivity.

\section{Preparation of Melts and Methods of Tests}

\section{Preparation of Melts}

The liquids investigated were made by melting in platinum crucibles the requisite amounts of raw materials of the purity ${ }^{1}$ used for optical glasses. The

1 A typical analysis of silica is $\mathrm{SiO}_{2}-99.71, \mathrm{Fe}_{2} \mathrm{O}_{3}-0.01, \mathrm{R}_{2} \mathrm{O}_{3}-0.11$, HF residue- 0.20 ignition loss-0.09. Potash is required to contain over $98 \%$ of $\mathrm{K}_{2} \mathrm{CO}_{3}$, negligible amounts of coloring oxides ( $\mathrm{Mn}, \mathrm{Cr}, \mathrm{Ni}, \mathrm{Fe}$ ) and be completely soluble in water. Soda ash is required to contain at least $58 \%$ of $\mathrm{Na}_{2} \mathrm{O}$, same negligible amounts of coloring oxides and be completely soluble. melts, weighing approximately $500 \mathrm{~g}$, were stirred with a motor-driven (propellor-type) platinum stirrer. When they seemed homogeneous, they were poured into iron molds.

\section{Chemical Analysis}

Samples from each melt were analyzed for alkali oxide content by evaporation to dryness on a steam bath with $\mathrm{HF}$ to the corresponding fluosilicate and followed by drying at $135^{\circ} \mathrm{C}$ to constant weight. With higher alkali content better reproducibility of the analyses was obtained by evaporation with $\mathrm{HF}$ and $\mathrm{H}_{2} \mathrm{SO}_{4}$ to the sulphate, followed by heating to constant weight at approximately $600^{\circ} \mathrm{C}$. Analyses were made also of many of the samples remaining from the individual determinations of surface tension.

\section{Measurement of Surface Tension}

The method for measuring surface tension in use in this laboratory [1] ${ }^{2}$ was that of determining the maximum pull exerted on a thin-walled platinum cylinder when its lower edge was in contact with the test liquid. In general the first determination of surface tension of any melt was made at $1,400^{\circ} \mathrm{C}$. Subsequent measurements were made at $100-\mathrm{deg}$ C intervals, decreasing the temperature until the glass was too viscous to yield in a reasonable time, or until crystallization occurred.

\section{Measurement of Density}

In order to obtain accurate values of surface tension with the method used, it was necessary to know the density of the liquid at the temperature of test. These densities were determined by a counterbalanced-sphere method [2]. Expansivities were calculated from the change of density with temperature.

${ }^{2}$ Figures in brackets indicate the literature references at the end of this paper 


\section{Results and Discussion}

\section{The System $\mathrm{Li}_{2} \mathrm{O}-\mathrm{SiO}_{2}$}

Table 1 gives the surface tension values obtained, and figure 1 shows the data in graphical form. Below 16 percent of lithia, surface tension measurements could not be made at temperatures less than $1,300^{\circ} \mathrm{C}$ because of crystallization. Above 20 percent of lithia the lowest temperatures at which surface tensions could be measured rose from $1,000^{\circ} \mathrm{C}$ to about $1,200^{\circ} \mathrm{C}$. The curves of surface tension versus temperature appear to converge with increasing temperature. It will be noted (fig. 1) that the surface tension values of liquids containing less than 20 percent of lithia increases with rise in temperature, which means that in this case the temperature coefficient of surface tension $(d \sigma / d t)$ has a positive sign. This result can be contrasted with familiar liquids whose surface tension decreases with rise in temperature, that is, $d \sigma / d t$ has a negative sign. In discussing changes in the magnitude of $d \sigma / d t$ of ordinary liquids it has been tacitly assumed in the literature that the sign is always negative and only the absolute values are of concern. However, in the present study liquids exhibiting both positive and negative temperature coefficients are encountered, and the algebraic sign as well as the magnitude must be kept in mind.

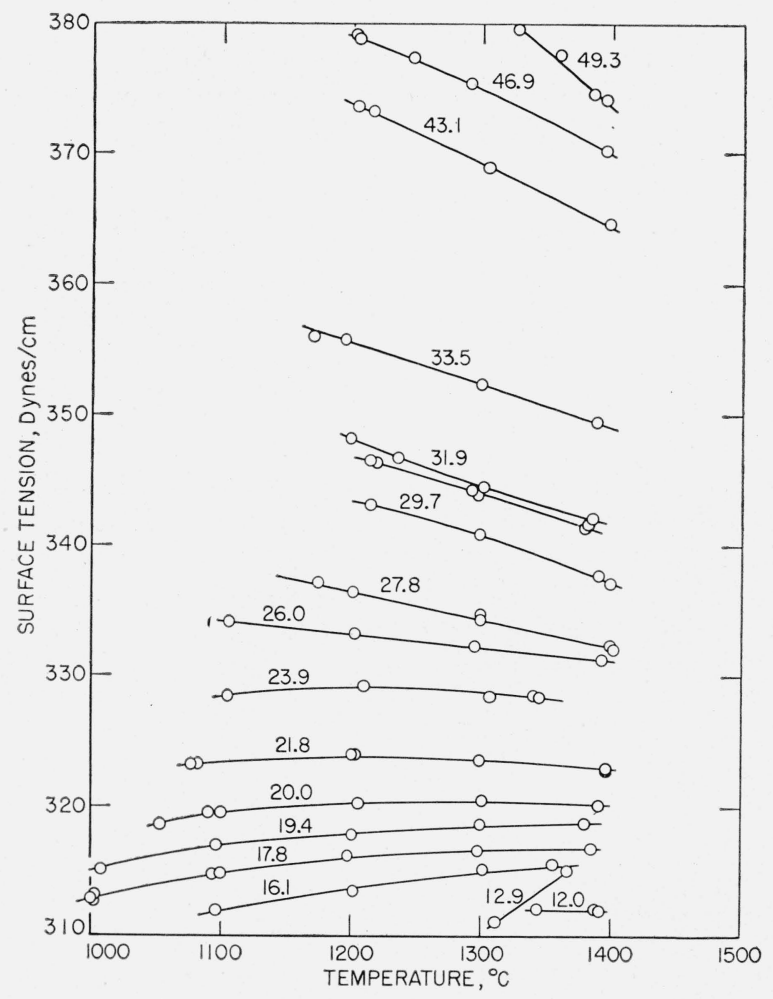

Figure 1. Surface tension of liquids in the system $\mathrm{Li}_{2} \mathrm{O}-\mathrm{SiO}_{2}$ as a function of temperature.

The percentage of $\mathrm{Li}_{2} \mathrm{O}$ is shown just above each curve.
The upper part of figure 5 shows a plot of the surface tensions of lithia-silica liquids at $1,300^{\circ} \mathrm{C}$ as a function of composition. The surface tension goes up with increasing lithia content. The value found by Jaeger [3] for the metasilicate composition (cross in fig. 5) is about 10 dynes/cm higher (2.8 $\%$ ) than that obtained in this investigation. The lower portion of figure 5 shows a plot of the temperature coefficient of surface tension at $1,300^{\circ} \mathrm{C}$ versus composition. The temperature coefficient becomes more negative with increasing amounts of lithia. Liquids containing less than 33.4 mole percent of lithia have positive temperature cofficients.

These data permit inferences regarding the properties of vitreous silica. Unless the curve (fig. 5) has a minimum in the region below 21.5 mole percent of lithia or shows other unusual dependence on lithia content, the surface tension of vitreous silica at $1,300^{\circ} \mathrm{C}$ is of the order of 300 dynes $/ \mathrm{cm}$. With the same reservations a parallel inference that the temperature coefficient of surface tension is positive may be made.

\section{The System $\mathrm{Na}_{2} \mathrm{O}-\mathrm{SiO}_{2}$}

Table 2 gives the results obtained with liquids in the soda-silica system, and figure 2 shows the results in graphical form. The effect of increasing temperature is to decrease the surface tension for a given composition and to decrease the magnitude

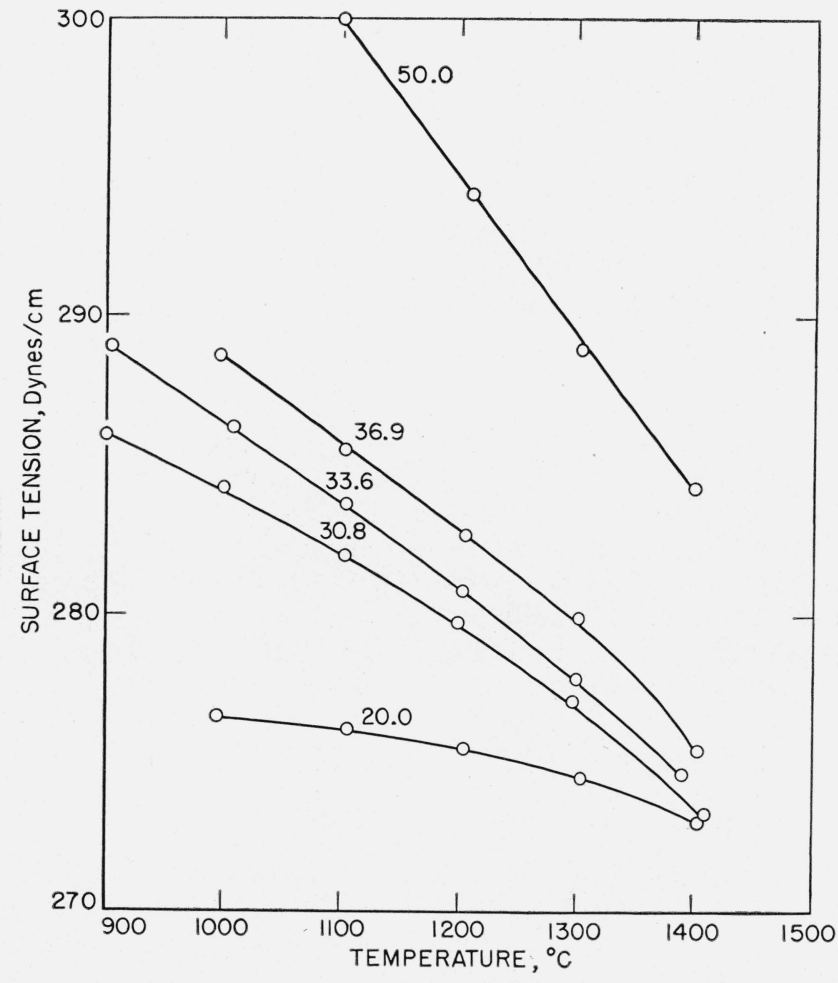

Figure 2. Surface tension of liquids in the system $\mathrm{Na}_{2} \mathrm{O}$ $\mathrm{SiO}_{2}$ as a function of temperature.

The percentage of $\mathrm{Na}_{2} \mathrm{O}$ is shown just above each curve. 
TABLE 1. Surface tension, temperature coefficient of surface tension, and expansivity of liquids in the system $\mathrm{Li}_{2} \mathrm{O}_{-} \mathrm{SiO}_{2}$

\begin{tabular}{|c|c|c|c|c|c|c|c|c|}
\hline \multirow{2}{*}{$\begin{array}{l}\text { Weight } \\
\text { percent } \\
\text { of } \mathrm{Li}_{2} \mathrm{O}\end{array}$} & \multirow{2}{*}{$\begin{array}{c}\text { Mole } \\
\text { percent } \\
\mathrm{Li}_{2} \mathrm{O}\end{array}$} & \multicolumn{5}{|c|}{ Surface tension at- } & \multirow{2}{*}{$\begin{array}{c}\Delta \sigma / \Delta t \text { at } \\
1,300^{\circ} \mathrm{C} .\end{array}$} & \multirow{2}{*}{$\begin{array}{l}\text { Volume } \\
\text { expan- } \\
\text { sivity }\end{array}$} \\
\hline & & $1,400^{\circ} \mathrm{C}$. & $1,300^{\circ} \mathrm{C}$. & $1,200^{\circ} \mathrm{C}$. & $1,100^{\circ} \mathrm{C}$ & $1,000^{\circ} \mathrm{C}$. & & \\
\hline 12.0 & 21.5 & $\begin{array}{c}\text { Dynes/cm } \\
312.1\end{array}$ & Dynes/cm & Dynes/cm & Dynes/cm & Dynes/cm & $(\text { Dynes } / \mathrm{cm})^{\circ} \mathrm{C}$. & $p p m /{ }^{\circ} \mathrm{C}$. \\
\hline 12.9 & 22.9 & 316.3 & 310.8 & & & & & 46.5 \\
\hline 16.1 & 28.6 & 316.5 & 315.1 & 313.5 & 311.9 & & +0.015 & 60.7 \\
\hline 17.8 & 30.3 & 316.8 & 316.7 & 316.2 & 314.7 & 312.8 & +.003 & 45.5 \\
\hline 19.4 & 32.6 & 318.8 & 318.4 & 317.8 & 316.9 & 314.8 & +.005 & 76.8 \\
\hline 20.0 & 33.4 & 320.1 & 320.2 & 320.0 & 319.4 & & 0 & 76.0 \\
\hline 21.8 & 35.9 & 322.7 & 323.5 & 323.9 & 323.3 & ........... & -0.006 & 87.7 \\
\hline 23.9 & 38.7 & 327.9 & 328.4 & 329.1 & 328.3 & ............ & -.006 & 81.3 \\
\hline 25.9 & 41.3 & 331.1 & 332.1 & 333.1 & 334.1 & - & -.010 & 97.2 \\
\hline 27.8 & 43.6 & 332.2 & 334.2 & 336.3 & 338.4 & -.......- & -.020 & 91.8 \\
\hline 29.7 & 45.9 & 337.1 & 340.8 & 343.4 & -........ & - & -.032 & 103.9 \\
\hline 31.9 & 48.5 & 341.8 & $\begin{array}{l}344.5 \\
343\end{array}$ & 348.1 & $\cdots+\cdots$ & - & -.032 & 112.3 \\
\hline 33.5 & 50.3 & $\begin{array}{l}341.0 \\
349.1\end{array}$ & $\begin{array}{l}343.9 \\
352.3\end{array}$ & $\begin{array}{l}346.9 \\
355.5\end{array}$ & - & ........... & $\begin{array}{l}-.030 \\
-.032\end{array}$ & 112.0 \\
\hline 43.1 & 60.4 & 364.4 & 369.1 & 373. 9 & - & - & -.048 & -...-. \\
\hline 46. 9 & 64.0 & 370.0 & $\begin{array}{l}374.9 \\
9\end{array}$ & 379.1 & 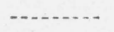 & ........ & -.046 & \\
\hline 49.3 & 66.2 & 373.6 & $\mathrm{a}[381.3]$ & & 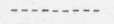 & 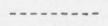 & -.0 & -..... \\
\hline
\end{tabular}

a Figures in brackets are extrapolated values.

TABLE 2. Surface tension, temperature coefficient of surface tension, and volume expansivity of some liquids in the system $\mathrm{Na}_{2} \mathrm{O}-\mathrm{SiO}_{2}$

\begin{tabular}{|c|c|c|c|c|c|c|c|c|c|}
\hline \multirow{2}{*}{$\begin{array}{l}\text { Weight } \\
\text { percent of } \\
\mathrm{Na}_{2} \mathrm{O}\end{array}$} & \multirow{2}{*}{$\begin{array}{l}\text { Mole per- } \\
\text { cent of } \\
\mathrm{Na}_{2} \mathrm{O}\end{array}$} & \multicolumn{6}{|c|}{ Surface tension at- } & \multirow{2}{*}{$\begin{array}{l}\Delta \sigma / \Delta t \text { at } \\
1,300^{\circ} \mathrm{C}\end{array}$} & \multirow{2}{*}{$\begin{array}{l}\text { Volume } \\
\text { expan- } \\
\text { sivity }\end{array}$} \\
\hline & & $1,400^{\circ} \mathrm{C}$ & $1,300^{\circ} \mathrm{C}$ & $1,200^{\circ} \mathrm{C}$ & $1,100^{\circ} \mathrm{C}$ & $1,000^{\circ} \mathrm{C}$ & $900^{\circ} \mathrm{C}$ & & \\
\hline $\begin{array}{l}20.0 \\
30.8 \\
33.6 \\
36.9 \\
50.0\end{array}$ & $\begin{array}{l}19.5 \\
30.1 \\
32.9 \\
36.2 \\
49.2\end{array}$ & $\begin{array}{c}\text { Dynes/cm } \\
273.1 \\
373.7 \\
274.4 \\
275.6 \\
284.3\end{array}$ & $\begin{array}{l}\text { Dynes/cm } \\
274.6 \\
277.0 \\
277.9 \\
279.9 \\
289.0\end{array}$ & $\begin{array}{l}\text { Dynes/cm } \\
275.6 \\
279.7 \\
280.9 \\
282.8 \\
294.6\end{array}$ & $\begin{array}{l}\text { Dynes/cm } \\
276.2 \\
282.1 \\
283.8 \\
285.6 \\
300.0\end{array}$ & $\begin{array}{c}\text { Dynes/cm } \\
276.6 \\
284.3 \\
286.4 \\
288.5\end{array}$ & $\begin{array}{c}\text { Dynes/cm } \\
286.0 \\
289.0\end{array}$ & $\begin{array}{c}(\text { Dynes } / \mathrm{cm}) /{ }^{\circ} \mathrm{C} \\
-0.008 \\
-.026 \\
-.030 \\
-.035 \\
-.052\end{array}$ & $\begin{array}{c}p p m /{ }^{\circ} \mathrm{C} \\
54 \\
66 \\
82 \\
88 \\
112\end{array}$ \\
\hline
\end{tabular}

of the difference in the surface tensions of the different compositions.

The upper part of figure 3 shows the effect of varying the soda content on the surface tension at $1,300^{\circ} \mathrm{C}$. The straight line was drawn through the data of other investigators, while the curved line was drawn through the data of the present investigation. Three of the other investigators $[4,5,6]$ used a maximum pressure method and one [7] used a modified drop-weight method. All the data are agreed in showing that the surface tension increases about 10 to 15 dynes $/ \mathrm{cm}$ as the soda content increases from 20 to 50 percent by weight. The values in the present investigation are lower by approximately 6 dynes $/ \mathrm{cm}(2.1 \%)$ than the average of the other investigators. In a previous investigation of the $\mathrm{PbO}-\mathrm{SiO}_{2}[8]$ system it was found that the maximum pull-on-cylinder method was higher than the drop-weight method [7] by about 9 dynes $/ \mathrm{cm}$. This suggests that differences between methods may be influenced by the compositions of the materials tested. The lower part of figure 3 shows a plot of the temperature coefficient of surface tension versus composition. Nearly all the available data indicate that the temperature coefficient becomes increasingly negative with increasing soda content.

As in the lithia-silica system the inference that vitreous silica at $1,300^{\circ} \mathrm{C}$ has a surface tension value of the order of 300 dynes/cm may be drawn unless the curve starts upward again as the silica content is increased. The data of Parmelee et al. [4] (hollow circles) suggest that this is indeed the case. The inference that $d \sigma / d t$ for vitreous silica is positive may also be drawn from its relation to soda content. Parmelee's [4] data (hollow circles) show, however, some evidence of a decrease or even a reversal of the tendency for the temperature coefficient to become more positive with decreasing soda content in the region below 25 percent of soda.

\section{The System $\mathrm{K}_{2} \mathrm{O}-\mathrm{SiO}_{2}$}

Table 3 gives the results of two sets of determinations on eight liquids of different $\mathrm{K}_{2} \mathrm{O}$ content, and figure 4 shows the data of the second set of determinations in graphical form. It may be seen that the effect on surface tension of differences in potash content is very small at $1,000^{\circ} \mathrm{C}$ but increases with increasing temperature. This divergence of the curves with increasing temperature is contrary to the experience with the lithia and soda silicates (figs. 1 and 2) where the different composition curves converge with increasing temperature. These contrasts in behavior correlate with the fact that both lithia and soda raise the surface tension of $\mathrm{SiO}_{2}$, whereas potash lowers it.

Some conclusions may be drawn regarding changes in surface concentration of potash by applying the Gibbs adsorption isotherm [9]. The divergence of the curves with increasing temperature means that the 
TABLE 3. Surface tension, temperature coefficient of surface tension, and volume expansivity of some liquids in the system $\mathrm{K}_{2} \mathrm{O}-\mathrm{SiO}{ }_{2}$

\begin{tabular}{|c|c|c|c|c|c|c|c|c|c|}
\hline \multirow{2}{*}{$\begin{array}{l}\text { Weight } \\
\text { percent } \\
\text { of } \mathrm{K}_{2} \mathrm{O}\end{array}$} & \multirow{2}{*}{$\begin{array}{l}\text { Mole } \\
\text { percent } \\
\text { of } \mathrm{K}_{2} \mathrm{O}\end{array}$} & \multirow{2}{*}{$\begin{array}{c}\text { Determi- } \\
\text { nation } \\
\text { number }\end{array}$} & \multicolumn{5}{|c|}{ Surface tension at- } & \multirow{2}{*}{$\Delta s / \Delta t \underset{\mathrm{C}}{\text { at }} 1,300^{\circ}$} & \multirow{2}{*}{$\begin{array}{l}\text { Volume } \\
\text { expan- } \\
\text { sivity }\end{array}$} \\
\hline & & & $1,400^{\circ} \mathrm{C}$ & $1,300^{\circ} \mathrm{C}$ & $1,200^{\circ} \mathrm{C}$ & $1,100^{\circ} \mathrm{C}$ & $1,000^{\circ} \mathrm{C}$ & & \\
\hline \multirow[t]{2}{*}{43.6} & \multirow[t]{2}{*}{33.0} & $\left\{\begin{array}{l}1 \\
2\end{array}\right.$ & $\begin{array}{l}\text { Dynes/cm } \\
207.7 \\
204.7\end{array}$ & $\begin{array}{c}\text { Dynes/cm } \\
212.1 \\
209.5\end{array}$ & $\begin{array}{c}\text { Dynes/cm } \\
216.1 \\
214.6\end{array}$ & $\begin{array}{c}\text { Dynes/cm } \\
221.1 \\
219.6\end{array}$ & $\begin{array}{c}\text { Dynes/cm } \\
223.0\end{array}$ & $\begin{array}{c}(\text { Dynes } / \mathrm{cm}) /{ }^{\circ} \mathrm{C} \\
-0.050\end{array}$ & $\begin{array}{c}p p m /{ }^{\circ} \mathrm{C} \\
119.4 \\
-\end{array}$ \\
\hline & & Avg & 206.2 & 210.8 & 215.4 & 220.3 & ......... & -.046 & -..... \\
\hline \multirow[t]{2}{*}{41.6} & \multirow[t]{2}{*}{31.2} & $\left\{\begin{array}{l}1 \\
2\end{array}\right.$ & $\begin{array}{l}209.0 \\
207.3\end{array}$ & $\begin{array}{l}214.1 \\
211.8\end{array}$ & $\begin{array}{l}218.2 \\
216.1\end{array}$ & $\begin{array}{l}221.8 \\
220.5\end{array}$ & $\begin{array}{l}226.2 \\
224.8\end{array}$ & -.044 & 102.0 \\
\hline & & Avg & 208.9 & 213.0 & 217.2 & 221.2 & 225.5 & -.045 & $\ldots$ \\
\hline \multirow[t]{2}{*}{38.7} & \multirow[t]{2}{*}{28.7} & $\left\{\begin{array}{l}1 \\
2\end{array}\right.$ & $\begin{array}{l}211.4 \\
208.7\end{array}$ & $\begin{array}{l}213.1 \\
212.8\end{array}$ & $\begin{array}{l}218.7 \\
216.6\end{array}$ & $\begin{array}{l}221.9 \\
220.7\end{array}$ & $\begin{array}{l}226.2 \\
224.6\end{array}$ & -.040 & 112.1 \\
\hline & & Avg & 210.0 & 213.0 & 217.6 & 221.3 & 225.4 & -.038 & $\ldots$ \\
\hline \multirow[t]{2}{*}{36.6} & \multirow[t]{2}{*}{26.9} & $\left\{\begin{array}{l}1 \\
2\end{array}\right.$ & $\begin{array}{l}211.0 \\
209.3 \\
\end{array}$ & $\begin{array}{l}212.8 \\
213.2 \\
\end{array}$ & $\begin{array}{l}216.7 \\
217.1 \\
\end{array}$ & $\begin{array}{l}220.9 \\
221.4 \\
\end{array}$ & $\begin{array}{l}225.2 \\
225.3 \\
\end{array}$ & -.039 & $\begin{array}{l}86.3 \\
-\ldots .\end{array}$ \\
\hline & & Avg & 210.2 & 213.0 & 216.9 & 221.2 & 225.2 & -.034 & -..... \\
\hline \multirow[t]{2}{*}{32.9} & \multirow[t]{2}{*}{23.8} & $\left\{\begin{array}{l}1 \\
2\end{array}\right.$ & $\begin{array}{l}213.9 \\
213.4 \\
\end{array}$ & $\begin{array}{l}216.5 \\
216.1 \\
\end{array}$ & $\begin{array}{l}218.6 \\
219.8 \\
\end{array}$ & $\begin{array}{l}221.4 \\
222.6 \\
\end{array}$ & $\begin{array}{l}227.6 \\
226.2 \\
\end{array}$ & -.032 & $\begin{array}{c}95.1 \\
-\end{array}$ \\
\hline & & Avg & 213.6 & 216.3 & 219.2 & 222.0 & 226.9 & -.028 & -..... \\
\hline \multirow[t]{2}{*}{29.9} & \multirow[t]{2}{*}{21.4} & $\left\{\begin{array}{l}1 \\
2\end{array}\right.$ & $\begin{array}{l}216.3 \\
216.6\end{array}$ & $\begin{array}{l}219.0 \\
218.5\end{array}$ & $\begin{array}{l}220.0 \\
220.5\end{array}$ & $\begin{array}{l}222.5 \\
224.1\end{array}$ & $\begin{array}{l}225.8 \\
227.4\end{array}$ & -.020 & $\begin{array}{r}74.1 \\
-\end{array}$ \\
\hline & & Avg & 216.4 & 218.8 & 220.2 & 223.3 & 226.6 & -.019 & -...... \\
\hline \multirow[t]{2}{*}{26.7} & \multirow[t]{2}{*}{18.8} & $\left\{\begin{array}{l}1 \\
2\end{array}\right.$ & $\begin{array}{l}218.8 \\
218.2\end{array}$ & $\begin{array}{l}220.4 \\
220.2\end{array}$ & $\begin{array}{l}224.2 \\
222.6\end{array}$ & $\begin{array}{l}224.6 \\
225.0\end{array}$ & $\begin{array}{l}226.8 \\
227.6\end{array}$ & -.022 & $\begin{array}{r}79.5 \\
-\end{array}$ \\
\hline & & Avg & 218.5 & 220.3 & 223.4 & 224.8 & 227.2 & -.024 & -..... \\
\hline \multirow[t]{2}{*}{23.9} & \multirow[t]{2}{*}{16.7} & $\left\{\begin{array}{l}1 \\
2\end{array}\right.$ & $\begin{array}{l}217.9 \\
219.9\end{array}$ & $\begin{array}{l}220.1 \\
222.0 \\
\end{array}$ & $\begin{array}{l}220.8 \\
223.9 \\
\end{array}$ & $\begin{array}{l}224.0 \\
225.5\end{array}$ & 228.4 & -.020 & $\begin{array}{l}70.4 \\
-\end{array}$ \\
\hline & & Avg & 218.9 & 221.0 & 222.4 & 224.8 & - & -.018 & -.... \\
\hline
\end{tabular}
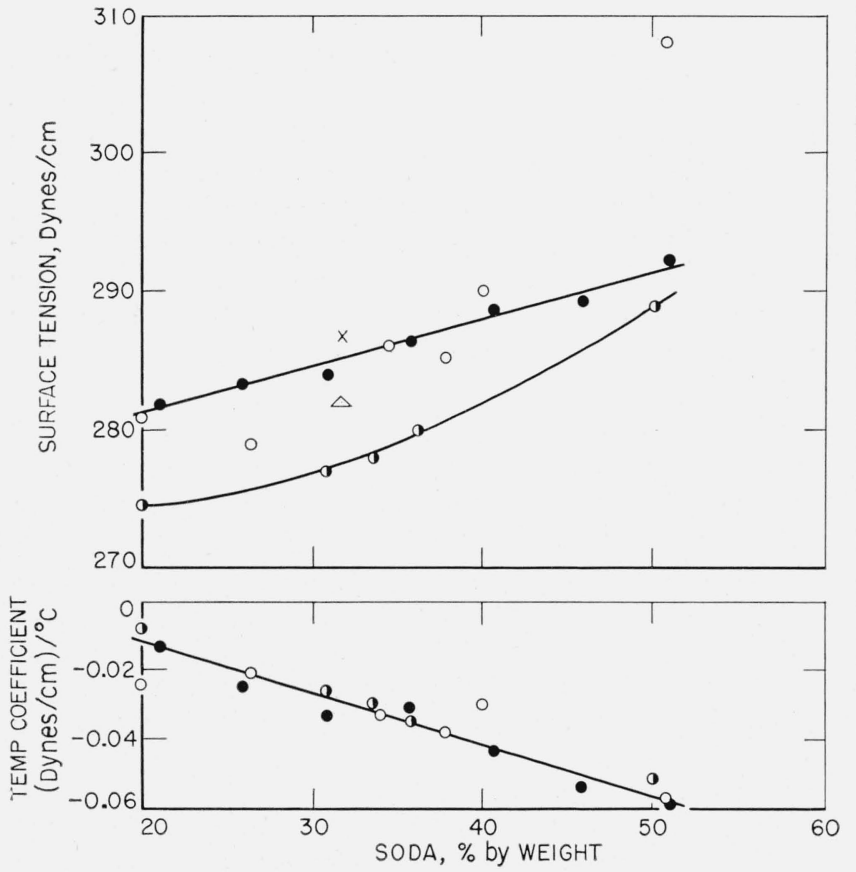

Figure 3. Surface tension and temperature coefficient of surface tension of liquids in the system $\mathrm{Na}_{2} \mathrm{O}-\mathrm{SiO}_{2}$ at $1,300^{\circ} \mathrm{C}$.

Hollow circles represent data of Parmelee et al. [4] with a bubble pressure method, filled circles represent data of Appen [7] with a modificd drop-weight
method, half-filled circles represent data of the present investigation, the cross method, half-filled circles represent data of the present investigation, the cross
renresents datum of Williams and Simpson [6] with a bubble pressure method, represents datum of Williams and Simpson [6] with a bubble pressure method,
and the triangle represents the datum of Amberg [5] with a bubble pressure method.

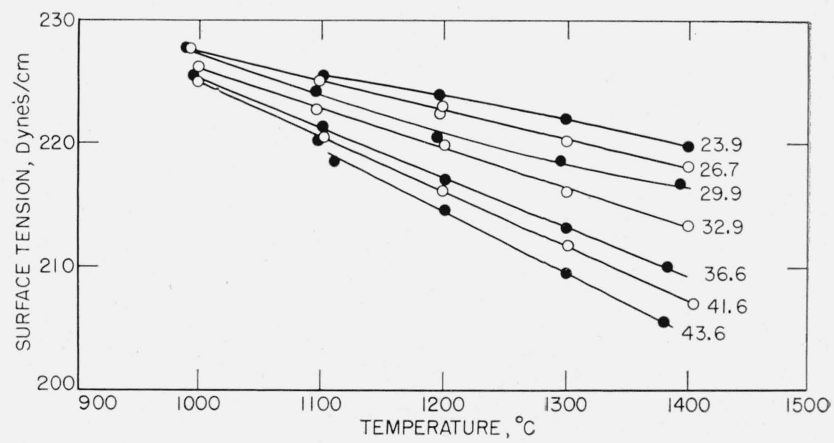

FIgure 4. Surface tension of iiquids in the system $\mathrm{K}_{2} \mathrm{O}_{-} \mathrm{SiO}_{2}$ as a function of temperature.

Second set of determinations. The percentage of $\mathbf{K}_{2} \mathrm{O}$ is shown to the right of each curve. 
change of surface tension with change in concentration of potash, $\Delta \sigma / \Delta c$ which may be called the concentration coefficient for convenience, increases in absolute magnitude with temperature. Since $\Delta \sigma / \Delta c$ is negative, the concentration of potash in the surface is greater than in the interior of the liquid according to the Gibbs adsorption isotherm. The increase in negative magnitude of $\Delta \sigma / \Delta c$ with increase in temperature means that the excess potash in the surface becomes greater as the temperature is raised. In the lithia and soda systems, the concentration coefficients are positive and become smaller as the temperature is raised. As there is less of these alkalies in the surface than in the interior and since this deficiency becomes less as the temperature is raised, the concentration of alkali in the surface increases with temperature.

In the above considerations, concentrations have been used instead of activities. A recent publication of Callow [10] has given the order of magnitude of the activity coefficients to be associated with the alkali concentrations. As the activity coefficients are always positive, they cannot change the algebraic sign of the concentration coefficients. Therefore, the general conclusions drawn here will not be affected.

The upper part of figure 5 shows a plot of the surface tension at $1,300^{\circ} \mathrm{C}$ as a function of the potash content. The effect of increasing the potash content is to lower the surface tension. There is a reason
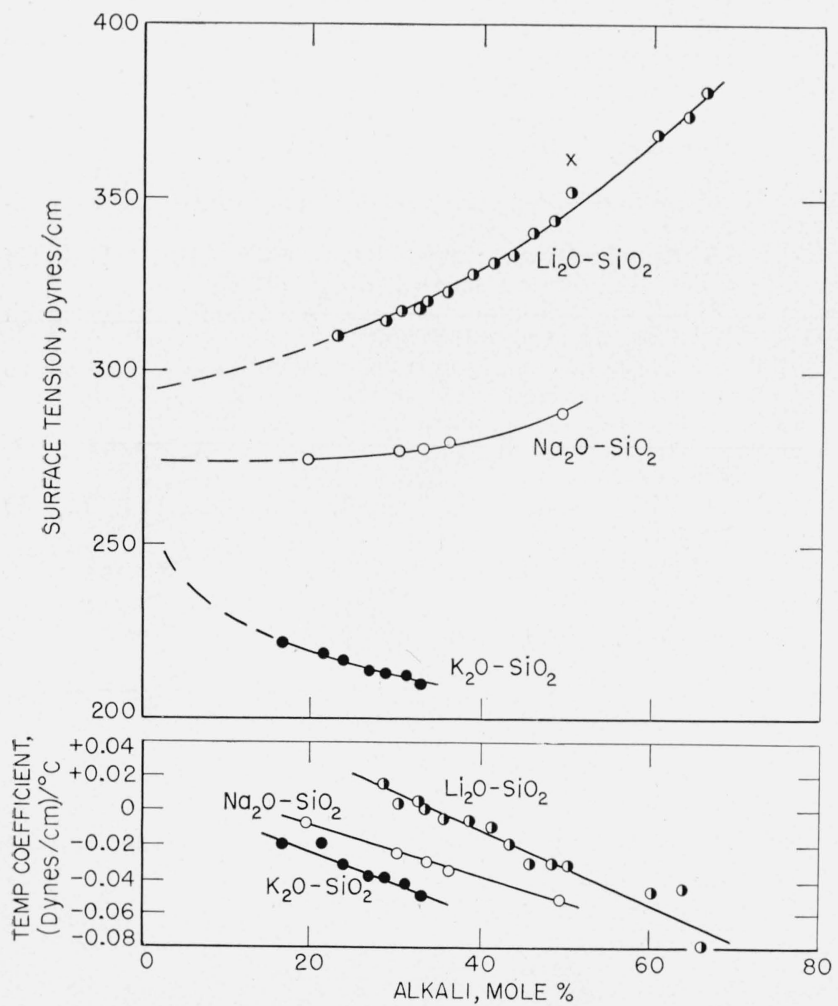

Figure 5. Comparison of the surface tension and temperature coefficient of surface tension at $1,300^{\circ} \mathrm{C}$ of alkaii silicate liquids as a function of the mole percent of alkali.

Cross was obtained by linear extrapolation of Jaegers [3] data above $1,380^{\circ} \mathrm{C}$. for not expecting a linear extrapolation of this curve to 0 percent of potash to yield a correct value for the surface tension of pure silica at $1,300^{\circ} \mathrm{C}$. When a substance lowers the surface tension of the liquid, the effect of the initial additions is usually much greater than that of the succeeding additions [9]. Therefore, linear extrapolation to 0 percent of $\mathrm{K}_{2} \mathrm{O}$ would be expected to give too low a value for the surface tension of pure silica at $1,300^{\circ} \mathrm{C}$.

The lower part of figure 5 shows the effect of composition on the temperature coefficient of surface tension at $1,300^{\circ} \mathrm{C}$. The general trend is for the temperature coefficients to become more negative with increasing $\mathrm{K}_{2} \mathrm{O}$ content. Linear extrapolation of the temperature coefficient to 0 percent of potash indicates a positive temperature coefficient of surface tension for pure silica at $1,300^{\circ} \mathrm{C}$, in agreement with the measurements of the $\mathrm{Li}_{2} \mathrm{O}-\mathrm{SiO}_{2}$ and $\mathrm{Na}_{2} \mathrm{O}-\mathrm{SiO}_{2}$ systems.

\section{Comparison of the Surface Tensions of the Alkali Silicates}

The upper part of figure 5 shows a plot of the surface tension at $1,300^{\circ} \mathrm{C}$ of the systems investigated versus the mole percent of alkali. The order $\mathrm{Li}>\mathrm{Na}>\mathrm{K}$ found is the same as that observed by Jaeger [3] for molten salts and by Badger [11] for equal molar alkali additions to a soda-lime-silica base glass.

The lower part of figure 5 shows a plot of the temperature coefficient of surface tension at $1,300^{\circ}$ $\mathrm{C}$ versus mole percent of alkali. Comparing the values of the coefficient (at the disilicate composition) the order $\mathrm{Li}>\mathrm{Na}>\mathrm{K}$ is found to hold in the sense that $\mathrm{Li}$ gives more positive coefficients than $\mathrm{Na}$ and $\mathrm{Na}$ gives more positive ones than $\mathrm{K}$.

\section{Temperature Coefficients and Expansivity}

The normal process tending to lower the surface tension as the temperature is raised is generally con-

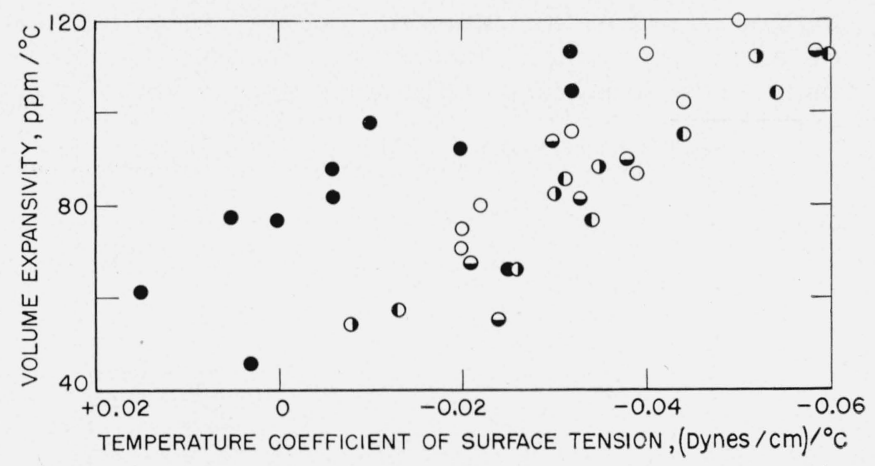

FIGURE 6. Volume expansivity at $1,300^{\circ} \mathrm{C}$ versus temperature coefficient of surface tension at $1,300^{\circ} \mathrm{C}$ of alkali silicate liquids.

Filled circles represent $\mathrm{Li}_{2} \mathrm{O}$ liquids, hollow eircles represent $\mathrm{K}_{2} \mathrm{O}$ liquids, and half-filled circles represent $\mathrm{Na}_{2} \mathrm{O}$ liquids. Circles whose right half is darkened represent data of the present investigation, those whose left half is darkened represent Appens [7] data, and those whose lower half is darkened represent data of Parmelee et al. [4] 
sidered to be associated with the decrease in the force of attraction between adjacent molecules as their average distance of separation increases with rising temperature. This suggests that the mechanism leading to negative temperature coefficients should have some relation to the expansivity. It has been deduced from theoretical considerations [9] that the ratio of the temperature coefficient ${ }^{3}$ of surface tension to that of cubical expansion should be constant. This deduction is based on the assumption that the liquids discussed are strictly homogeneous, that is, they each contain only one kind of molecule. Obviously, constancy of the ratio cannot be expected in solutions where different kinds of molecules exist and where the surface composition is generally different from that of the interior. Nevertheless, in a series of liquids containing one solute in different concentrations in the same solvent, one may expect some systematic relation between the two coefficients. The tendency for the temperature coefficient to increase in negative magnitude with increasing expansivity may be expected.

Figure 6 shows a plot of the volume expansivity versus the temperature coefficient of surface tension. In the case of the system $\mathrm{Na}_{2} \mathrm{O}-\mathrm{SiO}_{2}$, expansivity data were calculated from density data in the literature [12] combined with the data of the sphere method [2]. The general trend for the temperature coefficient of surface tension to become more negative as the expansivity increases is quite marked.

The authors invite attention to the large scatter in the temperature-coefficient data as well as the volume-expansivity data. The precision of such measurements is necessarily low because each value is derived from a small difference between two relatively large quantities. The differences between the two large quantities are often not much greater than the reproducibility of the method used so that a large scatter in the coefficients is to be expected. No exact laws can be deduced from such data; instead, only general trends may be observed.

In a previous publication [8] where the relation between temperature coefficient of surface tension and expansivity was discussed, the expansion data used were not in the same temperature region as that at which the surface tension was measured, principally because suitable data were not available. It

3 The temperature coefficient referred to in the literature [9] is $1(1 / \sigma)(d \sigma / d t)$, whereas the one used in this paper is $\Delta \sigma / \Delta t$, where $\sigma$ is the surface tension and $t$ the temperature. was tacitly assumed that the expansivities in the liquid region would parallel those in the solid range. Recent experience [2] in measuring densities has shown that such an assumption is not valid. The comparison of different properties must be based on measurements made over the same temperature range.

\section{Summary and Conclusions}

The surface tensions of a series of lithium, sodium, and potassium silicates have been measured. Increasing the lithia and soda content was found to raise the surface tension, whereas increasing the potash caused a lowering in surface tension. The order $\mathrm{Li}>\mathrm{Na}>\mathrm{K}$ was established for surface tension as well as for the temperature coefficient of surface tension. The surface tension-versus-temperature curves of differing alkali content were found to converge with increasing temperature in the case of the lithium and sodium silicates and to diverge in the case of the potassium silicates. Liquids containing less than 33 mole percent of lithia had positive temperature coefficients of surface tensions. Correlation was observed between alkali content, volume expansivity, and temperature coefficient of surface tension.

\section{References}

[1] L. Shartsis and A. W. Smock, J. Research NBS 38, 41 (1947) RP1771.

[2] L. Shartsis and S. Spinner, J. Research NBS 46, 176 (1951) RP2190.

[3] F. M. Jaeger, $Z$. fur Anorg Chemie 101, 179 (1917).

[4] Cullen W. Parmelee, Kenneth C. Lyon, and Cameron G. Harman, U. Ill. Bull. 36, No. 81 (June 6, 1939).

[5] C. R. Amberg, Thesis, Penn. State College (1948).

[6] R. M. Williams and H. E. Simpson, private communication.

[7] A. A. Appen, Optiko-Mekh Prom. 6 [3], 7 to 12; [12], $17 \mathrm{f}$ (1936); Ceram. Abs. 16 [2], 242 (1937).

[8] L. Shartsis, S. Spinner, and A. W. Smock, J. Research NBS 40, 61 (1948) RP1855.

[9] H. Freundlich, Colloid and Capillary Chemistry, p. 53 to 55 (E. P. Dutton and Co., New York, N. Y., 1922).

[10] R. J. Callow, Trans. Faraday Soc. 46, 663 (1950).

[11] A. E. Badger, C. W. Parmelee, and A. W. Williams, J. Am. Ceram. Soc. 20, 325 (1937).

[12] G. Heidtkamp and K. Endell, Glastech. Ber. 14, 89 (1936).

Washington, October 26, 1950. 